\title{
Social capital and health - a multilevel analysis of 25 administrative districts in Oslo
}

\author{
Kjetil A. van der Wel \\ Avdeling SAM, Høgskolen i Oslo, Postboks 4, St. Olavs plass, 0130 Oslo \\ Telefon: 22453570 (90641606) Telefaks: 22453600 E-post: kjetil.wel@sam.hio.no
}

\begin{abstract}
Background: Studies of place and health have recently gained increased interest among social researchers. This interest has brought society back to the study of health inequalities and drawn attention to the health effects of contextual psychosocial phenomena. Social cohesion, generalised trust, social networks and social participation are seen as being such phenomena in the social environment that affect health. Methods: This study investigates the association between social capital and self reported health in Oslo. I have used data from the Oslo Health Study 2000 (HUBRO), which includes 11,807 respondents residing in 25 administrative districts. For the multilevel analysis, contextual social capital was measured by aggregating the individual variables generalised trust and participation in voluntary organisations. In addition to the individual variables, the association between social capital and health was controlled for median income, economic inequality and educational level in the administrative districts. Results: In the models that only include the individual variables, both contextual trust and organisational participation had significant effects on self reported health. The associations between place, social capital, and health was attenuated and partly rendered insignificant by the other contextual variables. Conclusions: This study concludes that social capital is not associated with health when other contextual variables are taken into account, and suggests that previous findings may be mediated by median income and the educational level in the areas under study. However, strong conclusions cannot be drawn from this study due to low statistical power and the low response rate. None the less, the study supports the hypothesis that place matters for health.
\end{abstract}

\section{INTRODUCTION}

How does place affect health? The question has gained renewed interest in recent decades (Macintyre et al., 2002). Place effects can cause population health to vary between geographic areas in several ways. First, observed variations in health between places can simply appear due to the differences in the characteristics of the people that live in those places. This is called the 'compositional' place effect. Turning to the more unique (or real) place effects on health, these may be due to material conditions, such as the quality of water and air, housing, access to safe recreational areas and so on. Services provided by the community, like health and welfare services, public transport and schools, may also contribute to observed health inequalities between places. Sally Macintyre labels these two categories "contextual" place effects. Finally, sociocultural features like norms and values, trust and social integration, and the political and economic history of an area may affect the health of its residents. This dimension covers the "social climate" of a place and its reputation, and is labelled by Macintyre as the "collective dimension".

One aspect of the "collective dimension" of places is captured by the concept 'social capital', which is related to the more established concept of 'social cohesion' (Wilkinson, 1996). Social capital refers to properties of the social structure, such as the norms of reciprocity and social networks which facilitate cooperative action (Coleman, 1988; 1990; Putnam, 2000). Social capital is closely linked to social trust, which is also a commonly employed measure of the concept along with indicators of social participation (Putnam, 2004). Together, generalised trust and participation in voluntary organisations measure the cognitive and the structural component of social capital, respectively (Subramanian et al., 2002).

Richard G. Wilkinson's (1996) analysis of social cohesion, income inequality and health gave the social capital and health theory a broader conceptual basis and placed it within a larger frame of socioeconomic, cultural and political structures, adding the important dimension of social inequality. Wilkinson's hypothesis is that in wealthy societies, the relative income distribution is a more important health factor than absolute income distribution, because most of the population will enjoy living conditions where basic physiological needs are met (Wilkinson, 1996: 43-7). As a result, the spectrum of disease is no longer dominated by infectious diseases, but by chronic illness. This is known as the 'epidemiological transition'. Wilkinson does not entirely dismiss material explanations, as some critics claim, but he does argue that because of this transition, psychosocial explanations are becoming increasingly important for understanding health inequalities in 
modern societies. This view is largely supported by the work of Michael Marmot (Brunner \& Marmot, 1999; Marmot, 2005). Not only does your relative standing in the social hierarchy matter for your health and wellbeing, but so does the steepness of the hierarchy, regardless of your own place in it, Wilkinson argues. In this way, societies with high income inequality have higher mortality rates than societies with low income differences. The main reason for this, according to Wilkinson, is that societies with low income inequality are more cohesive or have more social capital (Wilkinson, 1996: 4).

One way to understand Wilkinson's model is that income inequality affects the level of social cohesion, solidarity, and social participation in a society, by affecting the actions that people take and their selfperceptions, based on their perception of the entire social hierarchy. Societies characterised by high income inequality and low social cohesion suffer from comparatively higher levels of conflict, less cooperation and solidarity, and more accidents and violence. At the individual level, people living in the lower social strata will experience more chronic stress and less control, resulting in short-sighted actions and unhealthy lifestyles and consumption (Wilkinson, 1996: 185-90).

Wilkinson's work has stimulated interest in the relationship between place and health, and the role of social capital, economic measures and material deprivation in this relationship, and hence, his work has strengthened the contextual notion of social capital. The concept of social capital is not fixed according to analytical level, but it is argued that its theoretical strength in public health research lies mainly at the contextual analytical level (Kawachi et al., 2004).

Social capital, being a contextual phenomenon, is hypothesised to act partly through social networks and social relations in its connection to health, and partly through individuals' sense of society or what might be called the social "climate" of a place. Places or neighbourhoods with a substantial stock of social capital may provide protection against stress and conflict, by facilitating cooperation. Such places can also stimulate health, by generating healthy norms and social controls and by promoting rapid diffusion of health information (Putnam, 2000; Kawachi et al., 1999).

Multilevel studies of social capital and health have thus far resulted in ambiguous findings. The connection between social capital and health seems to be clearer in studies using larger geographical units, and for studies conducted with data from the United States (Kawachi et al., 1999; Subramanian et al., 2001). The smaller the spatial units are, the weaker the findings, it seems (Subramanian et al., 2002; Mohan et al., 2005; Veenstra, 2005; Turell et al., 2006). Several studies have tested the effects on the connections between social capital and health, by introducing income inequality (Kawachi et al., 1999; Subramanian et al., 2001; Veenstra, 2005). Some of these studies also controlled for median income, resulting in insignificant coefficients for income inequality (Subramanian et al., 2001; Veenstra, 2005).

Few studies have simultaneously controlled for contextual and individual social capital (Kawachi et al., 2004). Subramanian et al. (2002) found a complex cross-level interaction effect where high trusting individuals were better off living in high trusting communities, while low trusting individuals had a negative health effect. Community trust became insignificant when controlled for individual trust. Veenstra (2005) and Mohan et al. (2005) controlled for individual social capital, but found no health effect for contextual social capital. In a recent study, Kim \& Kawachi (2006) found that individual social capital rendered two out of three social capital indicators insignificant.

In the present study, I will investigate the importance of two social capital indicators, generalised trust and participation in voluntary organisations, covering the cognitive and structural dimensions of the concept, for self reported health in 25 administrative districts of Oslo. Although Norway is a highly egalitarian country, health inequalities are marked, and this is especially true for Oslo, the capital city (Claussen \& Næss, 2002; Sund \& Krokstad, 2005). Health inequalities persist not only between social strata, but these inequalities also largely divide the city geographically, in terms of life expectancy (Hagen et al., 1994). In this analysis, I will employ multilevel methods that allow me to investigate contextual place effects controlled for individual properties, including individual level measures of social capital.

The research questions explored in this article are: (1) Are there any connections between indicators of social capital and self-reported health in the administrative districts of Oslo? (2) To what extent is this effect mediated by the population composition of the geographical units? (3) Are there any cross-level interaction effects - are the connections between social capital and health different for different social categories? (4) To what extent are the effects between social capital and health affected by contextual confounders: median income, income inequality and educational level?

\section{MeTHODS}

\section{Data}

In this study, I have analysed data from the Oslo Health Study 2000 (HUBRO), a population based survey linked to a wide range of public register data. Data on educational level in the administrative districts of Oslo were obtained from The Municipality of Oslo/ Statistics Norway.

The population targeted by the HUBRO survey includes all residents of Oslo born in the years 1924-25, 1940-41, 1955, 1960 and 1970, a total population of 40,888. The response rate was 46 per cent, leaving a net population of 18,770 individuals. 
Because of limitations in the statistical software, all missing cases for all of the variables had to be filtered off. In addition, respondents from two of the original 27 administrative districts (ADs) in Oslo had to be excluded, because the response rate was too low to produce reliable AD aggregates. As a result, the number of cases was reduced to 11,807 respondents nested within $25 \mathrm{ADs}$, or 28.9 per cent of the total population targeted by the HUBRO survey. The population of each $\mathrm{AD}$ ranges from approximately 7,000 to 30,000 inhabitants and the mean is about 20,000. The ADs will comprise the units to be investigated at level two in the multilevel analyses.

\section{Measures and definitions}

The dependent variable in this study is self-reported general health with four response categories; bad, not so good, good and excellent. These were collapsed into a dichotomous variable, where the two first indicate bad health, whereas the two latter indicate good health.

Contextual social capital is measured by aggregating the individual variables, generalised trust and participation in voluntary organisations, for each administrative district. Generalised trust is measured by the question; "Do you think that people will take advantage of you if you let them know too much about your self?" (Responses were either 'yes' or 'no'.) Participation in voluntary organisations is measured by the question; "In how many organisations or organised groups do you participate during your leisure time?" (Responses were either 'zero' or given in whole numbers.) This question was coded as a binary response $(0$ for 'zero' and 1 for one or more organisations.)

The association between social capital and health, will, at the contextual level be controlled for median income, income inequality and educational level in the administrative districts. Income inequality for each AD is estimated by dividing the standard deviation of the income distribution with the median of this distribution (Allison, 1978), and the educational level refers to the proportion of people holding a university or college degree in each AD.

Individual control variables in the regressions include the following variables: sex and age; the two oldest age-groups are collapsed so that five age-groups remain in the analyses, each one measured by an indicator variable. The variable measuring non-western immigrant status consists of people who were born outside Europe. Education is coded into five different levels; primary, lower secondary, higher secondary, lower tertiary and higher tertiary. Income is measured at the individual level and coded into deciles. In addition, individual social capital indicators are used: generalised trust and participation are measured by the same questions as their contextual counterparts. Having close friends is measured by the question "How many close friends do you have?" and responses were classified into $0-1$ and $2+$ friends.

\section{Statistical analysis}

The multilevel design of this study allows individual characteristics as well as contextual variables to be analysed in the same statistical model. The analyses are conducted using multilevel logistic regression in the MLwin software. The method of analysis used for the logistic regression is Marginal Quasi Likelihood (MQL), first order.

To produce meaningful estimates, all the continuous variables in the analyses had to be coded into centric scales around their means. When interpreting the coefficients from the logistic regressions, this should be taken into account.

Seven models will be estimated for each of the two social capital variables. In model 1 , the overall uncontrolled effect of social capital on health is estimated. In model 2, 3 and 4, different aspects of the composition of the ADs are introduced; sex, age and immigrant status (2), education and income (3), and finally, individual social capital variables (4).

The next step is to investigate if any cross-level interaction-effects can be detected. This is done by exploring several models. The explorations will not be reproduced in this article, although significant results from the interaction-analyses will be presented.

The final step is to introduce competing contextual variables. Because of the low statistical power of the analysis, due to the large number of respondents that had to be excluded and the exclusion of two ADs from the analysis, all the contextual variables could not be run in one model. So, in model 5 , median income is included. In model 6 , economic inequality and median income are included, and in model 7 , the proportion with a university or a college education will be tested against the social capital variables. Finally, all the variables are included in model 4.

The results from the multilevel logistic regression analyses are presented as odds ratios, and maximum effects for the association between social capital and health will be given for each model. This is done by subtracting the estimated probability for the AD with the highest social capital value from that of the AD with the lowest social capital value, assuming mean values on the included control variables in the model. The predicted logit is transformed into probabilities by the formula: $1 /(1+\exp (-$ Logit $))$.

\section{Results}

The mean number of respondents in the ADs is 474 (lowest $=121$ ). The mean level of respondents reporting good health across the 25 ADs is 78 per cent (variance 18 per cent). The mean level of people reporting trust in others is 93 per cent (variance 10 per cent), while the mean proportion for participation in voluntary organisations is 55 per cent (variance 22 per cent). The proportion holding a college or university degree is 32 per cent. Median income in the ADs is 272,579 
Table 1. The relationship between $\mathrm{AD}$ generalised trust level and self reported health, given in odds ratios $(95 \%$ CI), maximum effects for each model given in probabilities $\left(\mathrm{N}_{\mathrm{i}}=11807, \mathrm{~N}_{\mathrm{j}}=25\right)$.

\begin{tabular}{|c|c|c|c|c|}
\hline Model & 1 & 2 & 3 & 4 \\
\hline Maximum effect $(\mathrm{P})$ & 0.19 & 0.19 & 0.14 & 0.10 \\
\hline AD trust level & $1.11(1.06-1.15)$ & $1.13(1.09-1.18)$ & $1.08(1.06-1.11)$ & $1.07(1.04-1.10)$ \\
\hline Female & & $0.64(0.58-0.70)$ & $0.84(0.76-0.93)$ & $0.79(0.71-0.88)$ \\
\hline \multicolumn{5}{|l|}{ Age (ref: 30 years) } \\
\hline 40 years & & $0.51(0.43-0.61)$ & $0.52(0.43-0.62)$ & $0.52(0.44-0.63)$ \\
\hline 45 years & & $0.44(0.36-0.52)$ & $0.45(0.38-0.54)$ & $0.45(0.37-0.54)$ \\
\hline 60 years & & $0.21(0.18-0.25)$ & $0.26(0.22-0.31)$ & $0.25(0.21-0.30)$ \\
\hline 75 years & & $0.16(0.14-0.19)$ & $0.26(0.22-0.31)$ & $0.24(0.20-0.28)$ \\
\hline Non-western immigrant & & $0.50(0.40-0.64)$ & $0.56(0.44-0.70)$ & $0.71(0.55-0.91)$ \\
\hline \multicolumn{5}{|l|}{ Education (ref: primary) } \\
\hline Lower secondary & & & $1.40(1.20-1.63)$ & $1.38(1.18-1.60)$ \\
\hline Higher secondary & & & $1.64(1.41-1.92)$ & $1.58(1.35-1.85)$ \\
\hline Lower tertiary & & & $2.07(1.77-2.42)$ & $1.91(1.63-2.24)$ \\
\hline Higher tertiary & & & $2.85(2.28-3.56)$ & $2.62(2.08-3.28)$ \\
\hline Income & & & $1.12(1.10-1.14)$ & $1.11(1.09-1.13)$ \\
\hline \multicolumn{5}{|l|}{ Individual social capital } \\
\hline Mistrust & & & & $0.41(0.35-0.49)$ \\
\hline Organisational participation & & & & $1.17(1.06-1.29)$ \\
\hline $2+$ close friends & & & & $2.01(1.61-2.50)$ \\
\hline Constant & $3.66(3.37-3.96)$ & $14.07(11.91-16.62)$ & $5.82(4.77-7.11)$ & $3.31(2.47-4.43)$ \\
\hline
\end{tabular}

NOK (The difference between the highest and lowest median income is 96,879 NOK.) The mean income inequality is 0.6 (variance 0.5 ).

The odds ratio in model 1 shows that a one per cent increase, in the AD trust level is associated with an 11 per cent increased tendency to report good or excellent health, when individual properties are not taken into account. The maximum effect, or the effect on health for living in the district with the highest ratings for trust when this is compared to the district with the lowest ratings for trust, is 0.19 .

When controlling for sex, age-groups and nonwestern country of birth in model 2, assuming the values; male, aged 45, born in Europe, the maximum effect of trust on the probability of reporting good health is unchanged compared to model 1.

In model 3 , additional controls for education and income significantly attenuate the connection between district trust and health, but it is still significant. The maximum effect (in probabilities) for this model is 0.14 for typical values on the listed variables (45 years old, born in Europe, upper secondary school and income in the centre deciles). This nearly equals the maximum effects for income and education (not presented).

In model 4, the individual social capital variables, trust, participation and having close friends, are added. The coefficient for the district trust variable still holds its strength, and is still significant. The maximum effect gives the predicted probability for a person with typical values, as in model 3 , and, in addition, for the values trusting, not participating and having friends. Still, the typical Oslo-inhabitant who lives in the highest trusting district has a 0.10 higher probability of reporting good health, compared to one who lives in the lowest trusting district. To a great extent, however, this number depends upon the values given for the dichotomous individual social capital variables. The odds ratio for the AD trust level has not changed much compared to the previous model.

In Table 2, the connection between district participation and health is shown. It looks much the same as Table 3. All individual coefficients are removed from the table, but the analyses are run in the same way as in the previous analyses. Again, all AD participation coefficients are significant, but the predicted maximum probabilities are lower compared to those of the previous table.

The connection between social capital and health was not found to differ significantly for different social categories in the population, except from a significant cross-level interaction effect that was found for district participation level and income.

Figure 1 clearly shows that the highest income group does not benefit from living in a participating community, whereas the lowest income group reports substantially better health when living in the districts that have higher participation rates in Oslo. The figure is based on the prediction of typical values for the variables listed in model four in the previous table. 


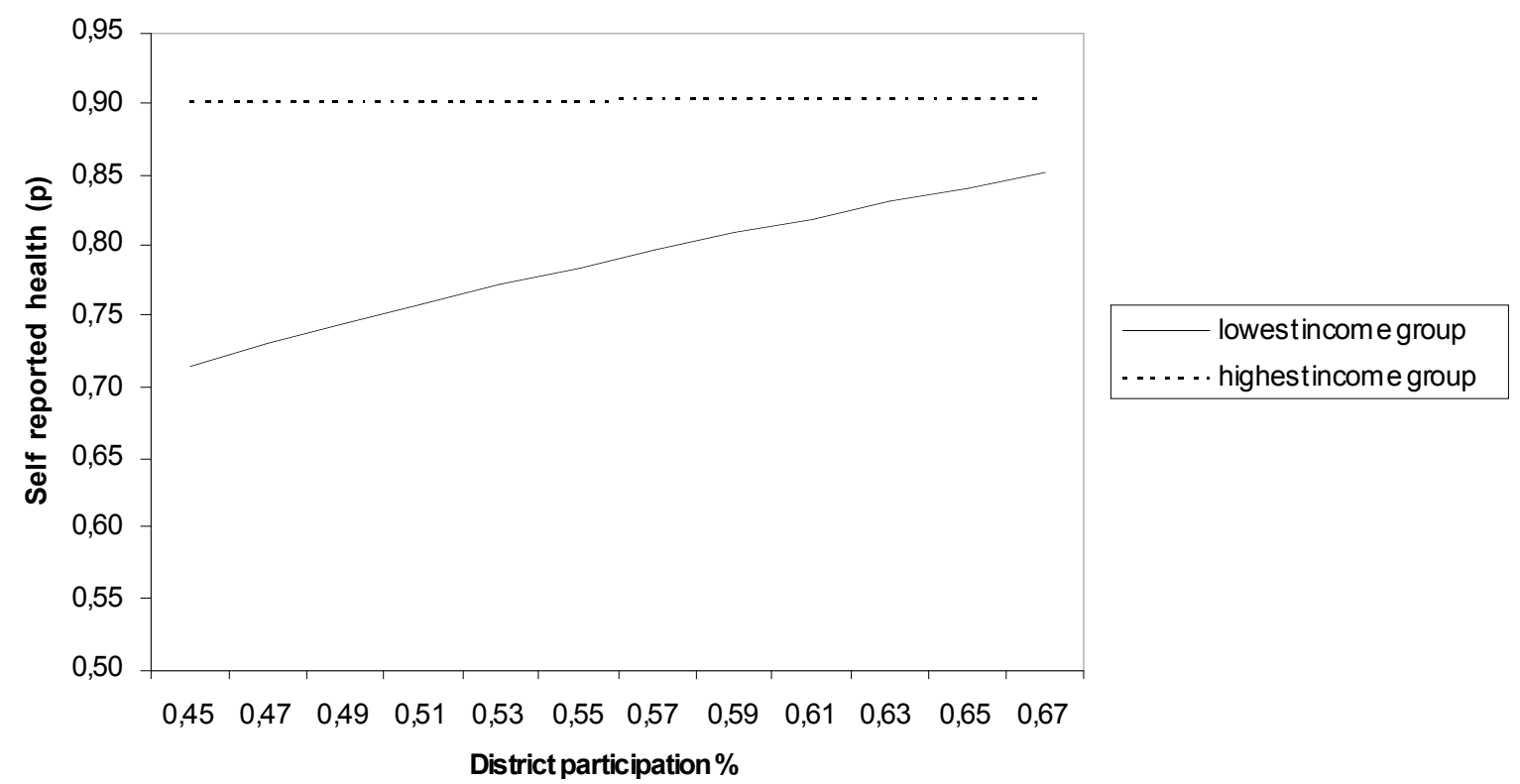

Figure 1. Cross level interaction effect between organisational participation level and income in their relationship to self reported general health, given in predicted probabilities based on model 4 , table 2 , typical values $\left(\mathrm{N}_{\mathrm{i}}=11807, \mathrm{~N}_{\mathrm{j}}=25\right)$.

Table 2. The association between $\mathrm{AD}$ organisational participation level and self reported good or excellent health given in odds ratios $(95 \% \mathrm{CI})$, maximum effects for each model given in probabilities $\left(\mathrm{N}_{\mathrm{i}}=11807, \mathrm{~N}_{\mathrm{j}}=25\right)$.

\begin{tabular}{lcccc}
\hline & Model 1 & Model 2 & Model 3 & Model 4 \\
\hline Max. effect & 0.06 & 0.10 & 0.08 & 0.06 \\
AD participation & $1.02(1.00-1.04)$ & $1.04(1.02-1.06)$ & $1.02(1.01-1.04)$ & $1.02(1.01-1.03)$ \\
\hline
\end{tabular}

The final step of this analysis is to introduce competing contextual variables (Tables 3 and 4). These models are based on the full model from the previous tables, including all the individual variables. Here, I have not estimated maximum effects as in the previous models because the locus of interest will be on the single relationships between the social capital variables and health when alternative context variables are included.

The results from the analyses of the connection between the district trust variable and health show first of all that the trust coefficients are considerably diminished, though still significant in the two first models (models 5 and 6). Controlling for the proportion in the administrative districts with higher education, the coefficient for district trust is finally rendered insignificant.

Turning to district participation, the table shows that the coefficients are insignificant in the models where the economic contextual variables are included.

\section{DISCUSSION}

In this study, I have analysed the association between social capital and health in 25 ADs of Oslo. In the simpler models of the analysis a quite strong relationship was found, even when controlling for individual social capital. Composition did reduce this relationship, but not as much as might be expected. Individual social capital measures did not affect the contextual effects of social capital, as found in other studies (Veenstra, 2005; Mohan et al., 2005; Kim and Kawachi, 2006). However, the relationship between social capital and health was rendered insignificant when controlling AD participation levels for median income and AD generalised trust levels for educational attainment. Finally, a cross level interaction effect was found for income and AD participation level: Low income individuals reported far better health when living in participating districts, while this effect was completely absent for high income individuals.

The study has several weaknesses. First of all, the cross-sectional data design does not allow any statement to be made regarding the causality between social capital and health. The direction of linkages is not necessarily an obvious one.

Next, the relatively weak statistical power, due to the low number of ADs, could have caused the social capital indicators to produce insignificant coefficients in the more advanced models (model 5-7). This may also be the reason for the few significant findings in the cross-level interaction analyses. It is recommended 
Table 3. The relationship between $\mathrm{AD}$ generalised trust level and self reported health, odds ratios ( $95 \%$ $\mathrm{CI})$, controlled for alternative contextual variables, based on model $4\left(\mathrm{~N}_{\mathrm{i}}=11807, \mathrm{~N}_{\mathrm{j}}=25\right)$.

\begin{tabular}{lccc}
\hline & Model 5 & Model 6 & Model 7 \\
\hline Trust level & $1.04(1.01-1.07)$ & $1.03(1.00-1.06)$ & $1.02(0.99-1.06)$ \\
Median income & $1.07(1.04-1.11)$ & $1.05(0.97-1.07)$ & \\
Level of income inequality & & $1.04(0.97-1.12)$ & \\
Proportion holding higher education & & & $1.12(1.06-1.19)$ \\
Constant & $3.52(2.63-4.71)$ & $3.54(2.64-4.75)$ & $3.44(2.57-4.60)$ \\
\hline
\end{tabular}

Tabell 4. The relationship between $\mathrm{AD}$ organisational participation level and self reported health, given in odds ratios $(95 \% \mathrm{CI})$, controlled for alternative contextual variables, based on model $4\left(\mathrm{~N}_{\mathrm{i}}=11807, \mathrm{~N}_{\mathrm{j}}=25\right)$.

\begin{tabular}{lccc}
\hline & Model 5 & Model 6 & Model 7 \\
\hline Organisational participation level & $1.01(0.99-1.02)$ & $1.00(0.99-1.01)$ & $1.01(1.00-1.02)$ \\
Median income & $1.09(1.05-1.12)$ & $1.06(1.01-1.11)$ & \\
Level of income inequality & & $1.05(0.98-1.13)$ & \\
Proportion holding higher education & & & $1.13(1.08-1.18)$ \\
Constant & $3.53(2.63-4.73)$ & $3.54(2.64-4.75)$ & $3.63(2.70-4.87)$ \\
\hline
\end{tabular}

that at least 20 units are included at each level of analysis (Kreft \& deLeeuw, 1998: 126). The number of level 2 units in this analysis is 25 , quite close to the minimum number recommended. Nevertheless, there are significant findings in the data for some of the models, and this makes it reasonable to support the conclusions that are drawn here.

Finally, the low response rate did skew the data used in this analysis. The original data sample has not been found to be significantly biased (Søgaard et al., 2004), but when the missing cases were excluded skewed differences between the original and the final sample used in the analysis appeared. When compared to the original sample, respondents in the final sample were slightly better off regarding measures of social position and health (table not presented). They were also slightly more trusting and participating. People born outside Western countries had the largest missing numbers. Although these biases were relatively modest, it may have led to an underestimation of the association between social capital and health, given the finding at stage three that low income groups have larger health benefits from social capital.

A comparative strength of the present analysis, as a multilevel social capital and health study, is that it allowed the use of two simple but conventional social capital variables for both levels of analysis. As a consequence, the effects of individual social capital could be taken into account.

An additional strength of the study is that the impact of the socio-cultural dimension of places was investigated in a more thorough way, by including educational level in addition to generalised trust. It can, of course, be argued that educational level is as much of an economic indicator as the other indicators, but the fact that educational level and income variables acted very differently in their relationships to the social capital variables and to self-reported health supports the conclusion that it actually measures different dimensions of places.

Assuming that the admitted weaknesses of the present study did not affect the results, how can these findings be interpreted? An important question is whether the ADs are appropriate social entities for investigating the relationship between social capital and health. Theoretical discussions and empirical findings provide no clear answers to this question. It may be true that smaller neighbourhoods would increase internal homogeneity, and would provide us with a clearer picture, because the chance that everybody is affected by the same social structures increases. On the other hand, studies employing small scale level two entities have led to few or weak findings in favour of the social capital and health hypothesis (Subramanian et al., 2002; Lochner et al., 2003; Mohan et al., 2005; Veenstra, 2005). On the contrary, the broad support for this relationship has been produced by studies of larger geographical units (Kawachi et al., 1999; Subramanian, 2001). The income inequality and health association has also been found mainly in studies employing larger geographical units (Wilkinson, 1996; Wilkinson \& Pickett, 2006; Dahl et al., 2006; Elstad et al., 2006). Based on this, a stronger health-connection for both the social capital indicators and income inequality might have been found by employing larger spatial units.

One might argue that contextual and compositional effects should not be seen as two isolated dimensions. Rather, they are more likely to be dependent upon one another (Macintyre et al., 2002). Hence, "overcontrolling" for individual characteristics may lead to an underestimation of the context, or reduce it to a 
residual-category. To examine this possibility, the more advanced models of the analysis (5-7) were run without the individual social capital variables, but this did not alter the conclusions (results not presented). The insignificance of this explanation also finds support in the modest change between model 3 and 4, where the individual social capital variables were introduced.

The context of Norway, in general, and Oslo, in particular, may also constitute a special case, when compared to the findings from the United States. The levels of organisational participation and generalised trust are relative high and the variations between the ADs are quite low in Oslo. It is possible that a connection between social capital and health may actually exist, but as long as the variations are fairly low, the connection cannot be revealed by internal comparisons. Nevertheless, it would still be true to say that social capital is not an important explanation of geographical health inequalities in Oslo.

The finding that the related concept of income inequality was not associated to health is probably caused by the relatively small size of the ADs. A connection has been found for larger regions in Norway, although no controls were made for social capital (Dahl et al., 2006). This interpretation is also supported by findings from a model that only includes median income and income inequality at the contextual level (not presented here). In a replication of Wilkinson's study, that included some additional countries and which widened the time span, Lynch et al. (2001) found that the initial relationship between income inequality and health disappeared. The United States was an exception, though, indicating that the US might represent a special case. This and similar studies have, however, been criticised because absolute income and material explanations are still highly relevant for understanding health differences (Muntaner \& Lynch, 2002; Pearce \& Davey Smith, 2003). The debate that ensued continues to reverberate (Lynch et al., 2004a; 2004b; Wilkinson \& Pickett, 2006). Similar conclusions can not be drawn from this study, due to the different scale of the spatial units. In addition, no measures of material deprivation have been included in this analysis. Nevertheless, this article does point out that the income inequality variable has only a limited interest for studies of social capital and health in small-scale societies.

Median income and educational level had a significant health effect, rendering $\mathrm{AD}$ participation and $\mathrm{AD}$ trust, respectively, insignificant. As a consequence, this article continues to support the hypothesis that socio-cultural and socio-economic dimensions of place matters for health.

Future research on social capital and health should approach the methodological problems experienced in this study by securing an adequate number of level-2units and should include a time-dimension. Controlling for spatial mobility might also be a sound research strategy.

\section{CONCLUSION}

The main findings of this study are that the connections between the conventional social capital variables; generalised trust and organisational participation, and health may be spurious, and that the place effects of educational attainment and income level may be the cause of those connections. Generally, this study still supports the hypothesis that socio-cultural and socioeconomic properties of places contribute in the shaping of geographical health inequalities.

\section{ACKNOWLEDGEMENTS}

This article is based on a master thesis in sociology, and the author was granted a scholarship by Oslo Research (Osloforskning). I would like to thank Arne Mastekaasa and Bjørgulf Claussen, who supervised my work, and Fredrik Piro, for useful help in setting up the statistical model in MLwin, and Espen Dahl, Marit Slagsvold and Ånen Ringard, for comments on the early project plan. In addition, I received valuable comments for this article from Sille Ohrem Naper and Espen Dahl, as well as from the referee employed by Norsk Epidemiologi. This article is still solely my own responsibility.

\section{REFERENCES}

Allison PD. Measures of inequality. Am Sociol Rev 1978; 43: 865-80.

Brunner EJ, Marmot M. Social organisation, stress and health. In: Marmot M, Wilkinson RG, eds. Social determinants of health. Oxford: Oxford University Press, 1999: 6-30.

Claussen B, Næss Ø. Dødelighet i Oslo etter ulikheter i yrkesklasse. Tidsskr Nor Laegeforen 2002; 122: 1867-9.

Coleman JS. Social capital in the creation of human capital. Am J Sociol 1988; 94: 95-120.

Coleman JS. Foundations of social theory. Cambridge: The Belknap Press of Harvard University, 1990.

Dahl E, Elstad JI, Hofoss D, Martin-Mollard M. For whom is income inequality most harmful? A multi-level analysis of income inequality and mortality in Norway. Soc Sci Med 2006; 63: 2562-74.

Hagen, K, Djuve AB, Vogt P. Oslo - den delte byen? FAFO-rapport. Oslo: FAFO, 1994

Elstad JI, Dahl E, Hofoss D. Associations between relative income and mortality in Norway: a register-based study. Eur J Public Health 2006; 16: 640-4. 
Idler EL, Benyamini Y. Self-rated health and mortality - a review of 27 community studies. J Health Soc Behav 1997; 28: 21-37.

Kawachi I, Kennedy BP, Glass R. Social capital and self-rated health: A contextual analysis. Am J Public Health 1999; 89: 1187-93.

Kawachi I, Kim D, Coutts A, Subramanian SV. Commentary: Reconciling the three accounts of social capital. Int J Epidemiol 2004; 33: 1-9.

Kim D, Kawachi I. A multilevel analysis of key forms of community- and individual-level social capital as predictors of self-rated health in the united states. J Urban Health 2006; 83: 813-26.

Kreft I, De Leeuw J. Introducing Multilevel Modelling. London: Sage Publications, 1998.

Lochner K, Kawachi I, Brennan RT, Buka SL. Social capital and neighborhood mortality rates in Chicago. Soc Sci Med 2003; 56: 1797-808.

Lynch J, Smith GD, Harper S, Hillemeier M, et al. Is income inequality a determinant of population health? Part 1. A systematic review. Milbank $Q 2004 a ; 82:$ 5-99.

Lynch J, Smith GD, Harper S, Hillemeier M, et al. Is income inequality a determinant of population health? Part 2. US National and regional trends in income inequality and age- and cause-specific mortality. Milbank $Q$ 2004b; 82: 355-400.

Macintyre S, Ellaway A, Cummins S. Place effects on health: how can we conceptualise, operationalise and measure them? Soc Sci Med 2000; 55: 125-39.

Marmot M. The status syndrome. Bloomsbury Publishing PLC, 2005.

Mohan J, Twigg L, Banard S, Jones K. Social capital, geography and health: a small-area analysis for England. Soc Sci Med 2005; 60: 1267-83.

Muntaner C, Lynch J. Social capital, class gender and race conflict, and population health: an essay review of Bowling Alone's implication for social epidemiology. Int J Epidemiol 2002; 31: 261-7.

Pearce N, Davey Smith G. Is social capital the key to inequalities in health? Am J Public Health 2003; 93: $122-9$.

Putnam RD. Bowling Alone. New York: Simon and Schuster, 2000.

Søgaard AJ, Selmer R, Bjertness E, Thelle D. The Oslo Health Study: The impact of self-selection in a large, population-based survey. Int J Equity Health 2004; 3 : 3.

Subramanian SV, Kim D, Kawachi I. Social trust and self-rated health in US communities: a multilevel analysis. $J$ Urban Health 2002; 79 (supp1. 1): S21-S34.

Subramanian SV, Kawachi I, Kennedy BP. Does the state you live in make a difference? Multilevel analysis of self-rated health in the US. Soc Sci Med 2001; 53: 9-19.

Subramanian SV, Jones K, Duncan C. Multilevel methods for public health research. In: Kawachi I, Berkmann L, eds. Neighborhoods and Health. New York: Oxford University Press, 2003: 65-111.

Sund E, Krokstad S. Sosiale ulikheter i helse i Norge - en kunnskapsoversikt. Oslo: Sosial og helsedirektoratet, 2005.

Turell G, Kavanagh A, Subramanian SV. Area variation in mortality in Tasmania (Australia): the contribution of socioeconomic disadvantage, social capital and geographic remoteness. Health Place 2006; 12: 291-305.

Veenstra G. Location, location, location: contextual and compositional health effects of social capital in British Columbia, Canada. Soc Sci Med 2005; 60: 2059-71.

Wilkinson RG. Unhealthy societies: the afflications of inequality. London: Routledge, 1996.

Wilkinson RG, Pickett KE. Income inequality and population health: a review and explanation of the evidence. Soc Sci Med 2006; 62: 1768-84. 